\title{
Obesity and Lipid Profile Study in Type 2 Diabetes Patients with Auditory and Reaction Time Deficits and Non-diabetic Control Subjects
}

\author{
Abhay Kumar Pandey,", Deepti Pandey², Abha Pandit ${ }^{3}$ \\ ${ }^{1}$ Department of Physiology, Government Medical College, Banda, India \\ ${ }^{2}$ Consultant Otorhinolaryngology, SLNM Charitable Trust Hospital, Varanasi, India \\ ${ }^{3}$ Department of Medicine, Index Medical College, Indore, India
}

Copyright $\bigcirc 2017$ by authors, all rights reserved. Authors agree that this article remains permanently open access under the terms of the Creative Commons Attribution License 4.0 International License

\begin{abstract}
Background: Obesity is lead component of metabolic syndrome and dyslipidaemia is shown to play diverse roles in type-2 diabetes and its complications resulting in morbidity and mortality Aim: Obesity and lipid profile changes in diabetes are to be assessed and their possible bearing on observed hearing loss and delayed reaction time reasoned with reference to scientific understanding. Method: 51 type-2 diabetes patients and 51 age sex matched non-diabetic controls are examined for obesity parameters and lipid profile. Possible relevance of the findings to observed complications in the patients is contemplated by literature reference. Conclusion: Obesity and dyslipidemia appear to be important in initiation, progression and complications of type 2 diabetes. Consensus needs to develop on routine management of diabetes with due cognizance of need to treat obesity and dyslipidemia, beyond usual focus on glycaemic control.
\end{abstract}

Keywords Type 2 Diabetes, Obesity, Dyslipidemia, Neurologic Complications of Diabetes

\section{Introduction}

Diabetes is a metabolic disorder of multiple etiologies, characterized by chronic hyperglycemia associated with abnormal carbohydrate, protein and lipid metabolism. Type 2 diabetes ensues upon metabolic syndrome. Obesity is leading characteristic of the syndrome and generates state of systemic chronic inflammation resulting in insulin resistance. Pancreatic beta cells over secrete insulin to overcome such deficit. When their ability to compensate fails typical failure of glycaemic control manifests as type 2 diabetes mellitus. Adipose tissue secrets cytokines and peptide hormones or adipokines as well as activated lipids, influencing energy metabolism in other tissues. Direct interaction of adipose tissue and brain is also implicated in integrating whole body energy regulation [1]. During prolonged caloric overload; adipocyte function causes inflammatory response, which in turn results in adipocyte dysfunction. Fat loaded adipocytes of obese individuals release more free fatty acids. That leads to excess synthesis of triglycerides (TGs), and secretion of VLDL rich triglycerides in to circulation. Through cholesteryl ester transfer protein (CETP), TG from VLDL is exchanged for cholesterol in HDL.TG-rich LDL and VLDL subsequently undergoes hydrolysis by hepatic lipase or lipoprotein lipase. This leads to formation of small dense LDL particles, which are more toxic and atherogenic [2]. Glycaemic control through proper management generally averts rise in total and LDL cholesterol. Continued state of obesity however would continue to worsen insulin resistance with consequent superimposition of hypertension along with atherosclerosis. Microvascular complications of diabetes with endothelial dysfunction drive occurrence of complications such as neuropathy, retinopathy, nephropathy etc. The hyperglycaemic state generates end products that trigger oxidative stress, including oxidation of lipoprotein fractions which set in vicious circle of endothelial dysfunction and further oxidative stress, with wide spread degenerative consequences in organs supplied by afflicted vessels. Mitochondrial dysfunction is a cardinal feature of type 2 diabetes that is aggravated by vasculopathy [3]. Role of diabetic dyslipidemia therefore has far larger implications in diabetic sequela.

In a study of 51 cases of type 2 diabetes receiving treatment and matched 51 non-diabetic control, striking $100 \%$ prevalence of sensory neural hearing losses in diabetics as opposed to only $29 \%$ in controls was revealed [4].Further investigations discovered delayed processing of auditory stimulus as well as prolonged visual reaction time in diabetics in contrast to non-diabetic controls [5].With $100 \%$ prevalence of hearing dysfunction, role of disease duration or degree of glycaemic control could not be deciphered. The 
control subjects showing sensorineural hearing loss exhibited prehypertensive profiles in contrast to normal hearing fellows in the group. In the present report observations of obesity and dyslipidemia in the compared groups of diabetic and non-diabetic subjects are presented. Attempt is made to discuss their relevance to earlier reported hearing loss and neurologic deficits.

\section{Subjects and Method}

The study was carried out on under treatment type 2 diabetes patients referred by medicine outdoor for auditory checkup in the otorhinolaryngology section at MGM medical college Navi Mumbai, during period of October 2007 to December 2008. Relevant details of protocol approval and recruitment of patients and controls in study were reported earlier [4]. Briefly, diagnosed type 2 diabetes patients of either sex or age matched controls each comprised of groups of 51.Sex distribution among diabetics was 19 males and 32 females. Among the nondiabetic control there were 29 males and 22 females. Either group was in 40 to 60 year age range. Median age of diabetic group was 51 year and that of non-diabetic control, 58 years. The controls were carefully screened for absence of significant clinical morbidity; any chronic drug prescription and any habit of tobacco and or alcohol consumption. Exclusion criteria adopted for either groups were blood pressure above $135 \mathrm{mmHg}$ systolic and/or $90 \mathrm{mmHg}$ diastolic; any prolonged (more than a week) hospitalization in past 3 years and significant illness in preceding one month. Antidiabetic drugs among patient group were only acceptable medications. Informed written consent was obtained from every participant with assurance of keeping personal identities undisclosed. Study protocol was approved by college research board.

\subsection{Measure of Obesity}

Demographic particulars of subjects were noted. Height was measured against Height scale and weight on weighing machine in ENT department. Waist circumference was measured with tape at midpoint between lower margin of thoracic cage and the top of iliac crest. Hip circumference was measured at the obvious widest level of hip. Body mass index was calculated by formula BMI=weight in $\mathrm{kg} /$ height in meters2.Waist/hip circumference (in $\mathrm{cm}$ ), ratio was calculated. Body fat percentage was calculated from BMI by using Deurenberg et al [6], formula, viz.

$\mathrm{BF} \%=1.2 \mathrm{xBMI}+0.23 \mathrm{xage}$ in years $-10.8 \mathrm{x}$ sex $($ female $=0 ;$ male $=1)-5.4$

Following anthropometric cut offs were adopted [7]:
BMI was analyzed as normal if up to 23.Above that level were the overweight/obese category.

Body fat $\%$ was analyzed as normal when under $25 \%$ in Men and under $30 \%$ in women higher $\mathrm{BF} \%$ constituted overweight and Obesity

Waist Circumference was normal if up to $85 \mathrm{~cm}$ in men and $80 \mathrm{~cm}$ in women. Waist /Hip ratio were normal when up to 0.88 in men and 0.81 in women.

Where BMI was high but $\mathrm{W} / \mathrm{H}$ ratio was in normal range persons were considered generalized overweight. In subjects where $\mathrm{W} / \mathrm{H}$ ratio exceeded 0.9 in men and 0.85 in women centralized obesity was labeled [8].

\subsection{Serum Lipid Profile}

After overnight fasting blood samples were drawn by venipuncture in cubital fossa. Serum was separated by centrifugation at $5000 \mathrm{rpm}$ for 10 minutes. The supernatant serum was pipette out and samples were analyzed in central facility Erba Mannheim Model XL 600 automated analyzer. The lipid profile included measurement of cholesterol by cholesterol oxidase method [9].LDL cholesterol $[10,11]$ and HDL cholesterol [12] were determined by direct kit method using liquid stable reagent( poly vinyl sulfonic acid and poly ethyl glycol, methyl ether coupled classic precipitation method), and TG by kit method [13].

Normal cut offs for various lipids were: Total Cholesterol up to $200 \mathrm{mg} / \mathrm{dl}$. LDL Cholesterol up to $100 \mathrm{mg} / \mathrm{dl}$. Triglycerides up to $150 \mathrm{mg} / \mathrm{dl}$ and HDL cholesterol above $60 \mathrm{mg} / \mathrm{dl}$ (www.cholesterolmenu.com/cholesterol-lev els-chart).

Distribution of individuals from the two groups under normal range or abnormal range values of above studied parameters were compared, with application of Chi Square test with Fishers correction as and when needed.

\section{Observations and Result}

16 of 51 diabetic subjects were overweight/obese $(\mathrm{OW} / \mathrm{Ob})$ as compared to 9 of 51 among the non-diabetic controls. Proportion of diabetic subjects with excess body fat percentage was also nearly double that seen in the non-diabetic controls .Little over tenth of non-diabetic subjects show central obesity type but more than half of the diabetic group show truncal obesity. The later distinction is statistically highly significant. Among the lipid parameters studied, the diabetes group manifested significantly higher triglyceride profiles than control group consistently. In regard to other lipids more subjects from diabetic group than controls exhibiter higher levels of total cholesterol and LDL cholesterol and lower level of HDL cholesterol. These differences were not statistically significant or consistent. 
Table 1. Distribution of subjects of T2DM and Control groups around normal cut off values of anthropometric parameters

\begin{tabular}{|c|c|c|c|c|c|c|c|c|c|c|}
\hline \multirow{3}{*}{\multicolumn{2}{|c|}{ Anthropometric Parameters }} & \multicolumn{9}{|c|}{ Distribution of number of subjects } \\
\hline & & \multicolumn{3}{|c|}{ Total } & \multicolumn{3}{|c|}{ Males } & \multicolumn{3}{|c|}{ Females } \\
\hline & & $\mathrm{T} 2 \mathrm{DM}$ & Control & $\mathrm{p}$ & $\mathrm{T} 2 \mathrm{DM}$ & Control & $\mathrm{p}$ & $\mathrm{T} 2 \mathrm{DM}$ & Control & $\mathrm{p}$ \\
\hline \multirow{2}{*}{ BMI } & Normal & 35 & 42 & - & 22 & 25 & - & 13 & 17 & - \\
\hline & High & 16 & 9 & - & 10 & 4 & - & 6 & 5 & - \\
\hline \multirow{2}{*}{$\mathrm{W} / \mathrm{H}$} & Normal & 22 & 45 & 0.01 & 18 & 26 & 0.01 & 4 & 19 & 0.001 \\
\hline & High & 29 & 6 & - & 14 & 3 & - & 15 & 3 & - \\
\hline \multirow{2}{*}{$\mathrm{BF} \%$} & Normal & 37 & 45 & - & 24 & 27 & - & 13 & 18 & - \\
\hline & High & 14 & 6 & - & 8 & 2 & - & 6 & 4 & - \\
\hline
\end{tabular}

Table 2. Distribution of subjects of T2DM and Control groups in anthropometric subcategories around cut off normal values of lipid parameters

\begin{tabular}{|c|c|c|c|c|c|c|c|c|c|c|}
\hline \multirow{3}{*}{\multicolumn{2}{|c|}{ Lipid Parameters }} & \multicolumn{9}{|c|}{ Distribution of number of subjects } \\
\hline & & \multicolumn{3}{|c|}{ Gen OW/Ob } & \multicolumn{3}{|c|}{ Central OW/Ob } & \multicolumn{3}{|c|}{ Non $\mathrm{OW} / \mathrm{Ob}$} \\
\hline & & $\mathrm{T} 2 \mathrm{DM}$ & Control & $\mathrm{p}$ & T2DM & Control & $\mathrm{p}$ & T2DM & Control & $\mathrm{p}$ \\
\hline \multirow{2}{*}{ TG } & Normal & 4 & 3 & 0.05 & 3 & 2 & - & 3 & 41 & 0.001 \\
\hline & High & 12 & 0 & - & 23 & 4 & - & 6 & 1 & - \\
\hline \multirow{2}{*}{ T CHOL. } & Normal & 7 & 3 & - & 10 & 3 & - & 5 & 39 & 0.01 \\
\hline & High & 9 & 0 & - & 16 & 3 & - & 4 & 3 & - \\
\hline \multirow{2}{*}{ LDL-C } & Normal & 5 & 3 & 0.05 & 15 & 3 & - & 6 & 38 & - \\
\hline & High & 11 & 0 & - & 11 & 3 & - & 3 & 4 & - \\
\hline \multirow{2}{*}{ HDL-C } & Normal & 11 & 3 & - & 19 & 4 & - & 7 & 40 & - \\
\hline & Low & 5 & 0 & - & 7 & 2 & - & 2 & 2 & - \\
\hline
\end{tabular}

OW- Over weight; Ob- Obese

\section{Discussion}

The diabetic subjects in the study had $100 \%$ prevalence of hearing loss in contrast to $29 \%$ in the controls [4], and deficit in central auditory processing as well as prolonged visual reaction times were demonstrated in the patients [5].The present study prominently reveals high prevalence of obesity, higher body fat percentage and hypertriglyceridemia in the diabetic patients. Current understanding may be revoked to appreciate clinical significance of the findings in context to observed complications. The issue of direct bearing of the findings for rational therapeutic management regimens addressing obesity and dyslipidemia for prevention /amelioration of complications needs resolution.

Various classifying parameters of overweight/obesity reflect the interactive risk posed by body composition for type 2 diabetes and its complications, specially the vasculopathies that contribute significantly to mortality world over. In Asia, increasing prevalence of type 2 diabetes and its complications despite generally lower body mass profiles as per international cut off, $25 \mathrm{~kg} / \mathrm{M} 2$ for overweight. Even at specific BMI, the Asians have higher percent of body fat than Europeans $[14,15]$. Although type 2 diabetes progression frequently occurs in obese, the association is dependent on genetic and epigenetic predispositions. The association of obesity to skeletal muscle insulin resistance is prerequisite for onset of type 2 diabetes and weight loss and gain correlate with increasing and decreasing insulin sensitivity respectively. The contribution of lipid overload and lipotoxicity in promoting obesity, by perturbing insulin signaling pathways through fatty acids in the skeletal muscle are now well appreciated. Normal lipid and glucose homeostasis, as well as normal insulin sensitivity requires fully functional adipose tissue.

Adipose dysfunction in obesity include secretion of abnormal levels of cytokines linked to insulin resistance; impairments in triglyceride storage and increase in lipolysis. These abnormalities in turn, contribute to increased fatty acids which inflict decreased insulin responsiveness in tissues as muscle, liver etc. in the obese. Obesity leads to chronic inflammatory state in fat depots, where adipocytes recruit macrophage infiltration. Inflammatory cytokines like TNF- $\alpha$ regulate crucial genes of lipid storage such as, transcription factor PPAR-gamma and related genes controlling fatty acid synthesis, esterification and sequestration as triglyceride in lipid droplets. Droplet associated proteins carry out sequestering of triglycerides in adipocytes as mechanism for furthering insulin resistance [1].

Type 2 diabetes promotes accelerated aging of the brain [16,17].Diabetics have 2 to 3 fold increased risk of developing vascular and Alzheimer type dementia [18-20]. 
Hyperinsulinemia plays major role in the cognitive decline $[21,22]$.Insulin resistance and advanced glycosylation end products are implicated in diabetic cognitive erosion [23]. Neurovascular dysfunction involving astrocytes in diabetes is found to associated cognitive dysfunction [24].A highly significant positive correlation between body mass index and both auditory and visual reaction time prolongation has been reported $[25,26]$.The sensory receipt and motor outflow speed remain constant in individuals life span. The obesity related prolongation of reaction times therefore points to delay occurring in nervous system processing of the sensory stimuli [27].

Oxidized lipoproteins are prominent carriers of oxidative damage. They play central role in initiation and acceleration of atherosclerosis. Patients with peripheral neuropathy particularly exhibit high levels of oxidized lipoproteins [28]. Extravasated lipoproteins get oxidized and glycated and cause widespread neurovascular injuries, which is seen as key to occurrence of complications, such as retinopathy [29].

Mitochondrial dysfunction is a critical vulnerability in type2 diabetes that worsened by free radical stress. Mitochondria are central to conversion of fatty acids and glucose to usable energy in form of ATP. Mitochondria utilize and break down fatty acids, which would accumulate in cell in event of mitochondrial dysfunction. Intracellular fat accumulation reduces expression and function of insulin receptors in tissues that are central to glucose metabolism, and this is partly pathogenic basis of type 2 diabetes $[30,31]$. High density of mitochondria prevails in auditory pathway along with GLAST proteins, which facilitates countering metabolic fatigue and protection against excitotoxic events $[3,32]$. NMDA and Kainate receptor subunits are expressed at auditory afferent postsynaptic densities [33]. Increased glutamate release in conditions as ischaemia etc. triggers $\mathrm{Ca} 2+$ influx via NMDA receptors in the dendrites. The induced overexcitation increases ATP demand, in face of diabetic mitochondrial dysfunction; protease and endonuclease activation and eventually neuron death [34].

\section{Conclusions}

Obesity and hyperlipidemia in diabetes suggest ample involvement in initiation, progression and complications. Further, their role in vasculopathy and mitochondriopathy deserves due cognizance and rectification when in excess $[35,36]$.The significance of weight reduction in diabetes management is highly reemphasized by present findings. Drug therapy with agents such as statins with added beneficial profiles may be regular adjunct in obese type 2 diabetics, especially with indications of dyslipidemia. Adjunct therapies aiming at abetment of the diverse harms of dyslipidemia and its interactions with other injurious factors are very desirable [37].Coenzyme Q application to abet mitochondriopathy represents one such example.

\section{REFERENCES}

[1] Guilherme A, Virbasius JV, Puri V, Czech MP. Adipocyte dysfunctions linking obesity to insulin resistance and type 2 diabetes. Nat Rev Mol Cell Biol. 2008; 9(5): 367-77

[2] Bays H. Atherogenic dyslipidemia in type 2 diabetes and metabolic syndrome: current and future treatment options. British Journal of Diabetes \& Vascular Disease 2003; 3: 356-360.

[3] Furness DN, Lawton DM. Comparative distribution of glutamate transporters and receptors in relation to afferent innervations density in the mammalian cochlea. J. Neurosci. 2003; 123(36):11296-304.

[4] Pandey AL. Study of hearing dysfunction in type 2 diabetes with reference to common risk factors. Journal of Diabetology, 2015; 3: 4(5 pages)

[5] Pandey AK, Pandey D. Central auditory processing and visual reaction time study in type 2 diabetes patients and age matched non-diabetic control subjects. Journal of biomedical and pharmaceutical research. 2016; 5(4): 11-15.

[6] Deurenberg P, Weststrate JA, Seidell JC. Body mass index as a measure of body fatness: age- and sex-specific prediction formulas. Br J Nutr. 1991; 65(2):105-14.

[7] Snehalatha C, Viswanathan V, Ramachandran A. Cutoff values for normal anthropometric variables in Asian Indian adults. Diabetes Care. 2003; 26 (5):1380-4.

[8] Misra A1, Vikram NK, Gupta R, Pandey RM, Wasir JS, Gupta VP. Waist circumference cutoff points and action levels for Asian Indians for identification of abdominal obesity. Int J Obes (Lond). 2006; 30(1):106-11.

[9] Khattack JK, Khan MA, Haq AU Arif M Minhas A. Occupational stress and burnout in Pakistan's banking sector. African journal of business management 2011, 5:810-817.

[10] Reddy KS. Cardiovascular Disease in Non-Western Countries. N Engl J Med 2004; 350:2438-40.

[11] Gaziano TA. Reducing the growing burden of cardiovascular disease in the developing world. Health Aff (Millwood) 2007; 26:13-24.

[12] Mezue K. The increasing burden of hypertension in Nigeria can a dietary salt reduction strategy change the trend. Perspect Public Health 2014; 134(6):346-52.

[13] Pyykkönen AJ, Räikkönen K, Tuomi T, Eriksson JG, Groop L, Isomaa B. Stressful life events and the metabolic syndrome: the prevalence, prediction and prevention of diabetes (PPP)-Botnia Study. Diabetes Care 2010; 33:378-84

[14] WHO Expert Consultation. Appropriate body-mass index for Asian populations and its implications for policy and intervention strategies. Lancet. 2004; 363(9403):157-163.

[15] Deurenberg-Yap M, Schmidt G, van Staveren WA, Deurenberg P. The paradox of low body mass index and high body fat percentage among Chinese, Malays and Indians in Singapore. Int J Obes Relat Metab Disord. 2000; 24(8): 1011-1017.

[16] Kent S. Is diabetes a form of accelerated aging? Geriatrics. 1976; 31(11):140, 145, 149-51.

[17] Perlmuter LC, Hakami MK, Hodgson-Harrington C, 
Ginsberg J, Katz J, Singer DE, Nathan DM. Decreased cognitive function in aging non-insulin-dependent diabetic patients. Am J Med. 1984; 77(6):1043-1048.

[18] Ott A, Stolk RP, Hofman A, van Harskamp F, Grobbee DE, Breteler MM. Association of diabetes mellitus and dementia: the Rotterdam Study. Diabetologia. 1996; 39(11): 1392-1397.

[19] Leibson CL, Rocca WA, Hanson VA, Cha R, Kokmen E, O'Brien PC, Palumbo PJ. Risk of dementia among persons with diabetes mellitus: a population-based cohort study. Am J Epidemiol. 1997; 145(4): 301-308.

[20] Yoshitake T, Kiyohara Y, Kato I, Ohmura T, Iwamoto H, Nakayama $\mathrm{K}$ et al Incidence and risk factors of vascular dementia and Alzheimer's disease in a defined elderly Japanese population: the Hisayama Study. Neurology. 1995; 45(6): 1161-1168.

[21] Kuusisto J, Koivisto K, Mykkänen L, Helkala EL, Vanhanen $\mathrm{M}$, Hänninen $\mathrm{T}$, Essential hypertension and cognitive function. The role of hyperinsulinemia. Hypertension. 1993; 22(5): 771-779.

[22] Atiea JA, Moses JL, Sinclair AJ. Neuropsychological function in older subjects with non-insulin-dependent diabetes mellitus. Diabet Med. 1995; 12(8): 679-685.

[23] Zimmet P, Alberti KG, Shaw J. Global and societal implications of the diabetes epidemic. Nature. 2001; 414(6865): 782-787.

[24] Mogi M, Horiuchi M. Neurovascular coupling in cognitive impairment associated with diabetes mellitus. Circ J. 2011; 75(5): 1042-1048.

[25] Nikam LH, Gadkari JV. Effect of age, gender and body mass index on visual and auditory reaction times in Indian population. Indian J Physiol Pharmacol. 2012; 56(1): 94-99.

[26] Skurvydas A, Gutnik B, Zuoza AK, Nash D, Zuoziene IJ, Mickeviciene D. Relationship between simple reaction time and body mass index. Homo. 2009; 60(1): 77-85.

[27] Marsh AP, Geel SE. The effect of age on the attentional demands of postural control. Gait Posture. 2000; 12(2): 105-113.

[28] Tsuzura S, Ikeda Y, Suehiro T, Ota K, Osaki F, Arii K, Kumon Y, Hashimoto K. Correlation of plasma oxidized low-density lipoprotein levels to vascular complications and human serum paraoxonase in patients with type 2 diabetes. Metabolism. 2004; 53(3): 297-302.

[29] Yu JY, Lyons TJ. Modified Lipoproteins in Diabetic Retinopathy: A Local Action in the Retina. J Clin Exp Ophthalmol. 2013; 4(6). pii: 314.

[30] Lowell BB, Shulman GI. Mitochondrial dysfunction and type 2 diabetes. Science. 2005; 307(5708): 384-387.

[31] Patti ME, Corvera S. The role of mitochondria in the pathogenesis of type 2 diabetes. Endocr Rev. 2010; 31(3): 364-395

[32] Liberman MC. Single-neuron labeling in the cat auditory nerve. Science. 1982; 216(4551): 1239-1241.

[33] Puel JL, Ruel J, Guitton M, Pujol R. The inner hair cell afferent/efferent synapses revisited: a basis for new therapeutic strategies. Adv Otorhinolaryngol. 2002; 59:124-30.

[34] Parsons MP, Raymond LA. Extrasynaptic NMDA receptor involvement in central nervous system disorders. Neuron. 2014; 82(2): 279-293.

[35] Pandit A Pandey AK Atherosclerosis: current perspectives Apollo medicine 2015 13:10-16

[36] Pandit A Health risks of obesity Chettinad health city medical journal 2015,4(1):32-35

[37] Pandit A Pandey AK Obesity context of type2 diabetes and medication perspectives Apollo medicine 2015: dx.doi.org/10.1016/j.apme.2015.08.001 